Article

\title{
The correlation between sleep quality and the prevalence of obesity in school-age children
}

\author{
Beatrix Elizabeth, Dessie Wanda, Efa Apriyanti \\ Department of Pediatric Nursing, Faculty of Nursing, Universitas Indonesia, Depok, West Java, Indonesia
}

\begin{abstract}
Background: The prevalence of obesity increases year by year. Sleep quality is considered to be one of the obesity causes. The current average sleep range of children in Indonesia was 6-7 hours. This study aims to analyze whether the sleep quality affects the prevalence of obesity in children.

Design and methods: This study used prospective cohort as the research method. The samples consisted of 37 primary schoolage children $\left(4^{\text {th }}-6^{\text {th }}\right.$ grade $)$ from West Java and Sumatra. The respondents were selected using snowball sampling technique due to pandemic situation during data collection period. The data were collected by using PSQI and sleep logs (within a month).

Results: The statistical results show that there were 19 obese and 18 non-obese children. Fourteen out of 19 obese children were boys, while among not obese children, the number of boys and girls were similar. Twelve out of 19 obese children had poor sleep quality (63.2\%), while most of the non-obese children had good sleep quality $(83.3 \%)$. Based on the chi-square statistic, the pvalue $=0.011<(0.05)$ indicating that $\mathrm{H}_{0}$ was rejected, which means there was a correlation between sleep quality and obesity, with $\mathrm{OR}=8.571(95 \% \mathrm{CI}: 1.818-40.423)$. In another words, the children with poor sleep quality were likely to experience obesity 8.6 times greater than those who had good sleep quality.

Conclusions: This study found there were correlations between dietary intake, physical activity, sleep quality, and obesity in school-age children. The most dominant factor related to obesity in school-age children is the habitual sleep efficiency $(\mathrm{OR}=12.354)$.
\end{abstract}

\section{Introduction}

Obesity in school-age children (6-12 years) is a serious problem because it will continue into adulthood. Obesity in children might increase the risk of type 2 Diabetes Mellitus (DM). It might also cause impaired glucose metabolism and degenerative diseases. Overweight children were not only at risk to experience health problems, but also motor and mental development delays compared to their friends of the same age with normal weight. ${ }^{1}$
The prevalence of obesity in children aged 5-19 years in 2025 is estimated to be more than $18 \% .^{2}$ In 2017, Organization for Economic Cooperation and Development (OECD) found that the prevalence of children aged 15 years with obesity in Denmark and US were $10 \%$ and $31 \%$ respectively. ${ }^{3}$ The prevalence of obesity in developed countries like America, Europe, and East Mediterranean were considered high, i.e. more than 35\%. ${ }^{4}$

Meanwhile, the prevalence of obesity in Asia-Pacific also increases rapidly. The prevalence of obesity in East Asia and West Asia reached $24.5 \%$ and $11.9 \%$ respectively. ${ }^{5}$ Indonesia has the highest rate of obesity cases in Southeast Asia (12\%), followed by Thailand (11\%), Malaysia (7\%), Philippines (5\%), Myanmar (3\%), Laos $(2 \%)$, and Cambodia $(2 \%) .{ }^{6}$ Based on the data from Basic Health Research in 2018, the prevalence of obesity in Indonesia was $31.0 \%$ with the highest prevalence at age 5-12 years, i.e. $18.8 \%$. If this continues, the prevalence of obesity in Indonesia will continue to increase. Because of obesity, children oftentimes get bullied and have low self-esteem. ${ }^{7}$ Obese children feel embarrassed to interact because some of their friends tease them and reluctant to be friend with them. ${ }^{8}$ Moreover, children with obesity might also experience growth disorders, particularly motor development. ${ }^{9}$ There are several risk factors of obesity, namely parent's genes, lack of activity, and poor diet. ${ }^{10,11}$ Sleep disorder can also cause obesity. Sleep disorder is a general complication from obesity that contributes to exacerbate obesity-related complications. Sleep disorder affects the hormones and the metabolism in human body. The abnormal hormones and the metabolism might increase the intake of unhealthy food and cause overweight. ${ }^{12}$ The average sleep range of children in Indonesia was 6-7 hours out of their 10 hours sleep needs. It was because they have many tasks from school, extracurricular activity or supplementary tutoring, and also schools in Indonesia starts at 7.00 a.m. and ends at 2 p.m. ${ }^{13}$

Obesity prevention becomes a public health challenge for nurses, indeed there is a decrease in obesity prevalence, but it is still considered slow. In light of this, the researcher is interested to conduct a study related to sleep quality that affects the obesity prevalence. Until recently, the study that correlates sleep quality and obesity is scarce in Indonesia.

Significance for public health

The incidence of obesity can be caused by genetics from parents, changes in lifestyle and diet. Obesity in childhood will carry over to adulthood and increase the risk of children developing degenerative diseases later in life. Several studies on risk factors and obesity prevention have focused more on children's nutrition and physical activity. Meanwhile, other risk factors such as sleep quality are not the main focus of obesity. Research that analyzes the effect of sleep quality on obese children is still limited. This study wanted to see the effect of sleep quality on the incidence of obesity in school-age children. 


\section{Design and Methods}

This study was an observational study with prospective cohort design. Prospectively, both groups were observed for the factors that might and might not be affected. This study aimed to find the correlation between the independent variable as the risk factor and dependent variable as the effect, and assess the correlation between these two variables with the confounding variable through a temporary measurement. This research was conducted from June 2020 to October 2020. The samples of this study were 37 children who were selected by using snowball sampling technique. The inclusion criteria of the respondents in this study, namely the children of $4^{\text {th }}, 5^{\text {th }}$, and $6^{\text {th }}$ grade aged $9-12$ years, the parents are willing to be the respondents, and the children are not having any of these conditions, such as hypothyroidism, polycystic ovary syndrome, Cushing's syndrome, etc.

This study has been approved by ethics committee Faculty of Nursing Universitas Indonesia, Depok, with number SK41/UN.2.F12.D1.2.1/ETIK.FIK.2020. For respondent who participated in the research, fill out the Informed consent form. The respondents who agreed to participate in this study received a characteristic questionnaire to identify their characteristics, including age, sex, school, and parent's phone number. Their parents were required to fill in the sleep logs for a month, which were sent by the researcher every morning via WhatsApp. The researcher collected the filled daily sleep log and sent it back to the parents after a month. The recaps of filled sleep log became the reference in filling the Pittsburg Sleep Quality Index (PSQI). ${ }^{14,15}$

PSQI was used to assess the sleep quality comprising of 7 components to describe the subjective sleep quality, sleep latency, sleep efficiency, sleep disturbance, use of sleeping medication, activity that might cause sleep disruptions, and daily activity related to sleep.

The physical activity was assessed from the number of steps by using smartwatch. The parents were informed to install smartwatch on the active children's wrist. Smartwatch was worn since waking up until before sleeping, and was only allowed to be put off while bathing. Steps less than 5,000/day is considered as light-intensity activity, and steps more than 5,000/day is considered as moderateintensity activity. The activity assessment using this smartwatch was conducted for 7 days.

The children's dietary intake was assessed by using Modified Child Nutrition Questionnaire (CNQ). ${ }^{16}$ This questionnaire consisted of 17 questions which should be filled by the parents. They were assessed for what they have consumed within 7 days, both meals and drinks. The questionnaire results were divided into two groups based on the median (score 24.00): if the score from ques- tionnaire $\geq$ median (24.00), it was categorized to excessive dietary intake, and if the score $\leq$ median then it was categorized into inadequate dietary intake.

\section{Results}

Based on the characteristic description, it can be seen that most of the school-age children, 23 out of 37 , were male (62.2\%), 20 out of 37 had excessive dietary intake $(54.1 \%)$, and 22 out of 37 indicated light-intensity physical activity $(59.5 \%)$. The characteristics is demonstrated in Table 1.

Assessing the correlation between dietary intake and obesity, it was found that most of the obese children (73.7\%) had excessive dietary intake, while most of the non-obese children (66.7\%) had inadequate dietary intake. Based on the Chi-square statistic, it was found that the $\mathrm{p}$-value $=0.033<(0,05)$ indicating $\mathrm{H}_{0}$ was rejected, which means there was a correlation between dietary intake and obesity, with $\mathrm{OR}=5.600$ (95\% CI: 1.360-23.059). This statistics result means that the children who had excessive dietary intake were likely to experience obesity 5.6 times greater than those who had inadequate dietary intake, as can be seen in Table 2 .

Based on the chi-square statistic, it resulted p-value $=0.032<$ $(0,05)$ indicating $\mathrm{H}_{0}$ was rejected, which means there was a correlation between physical activity and obesity, with $\mathrm{OR}=5.893(95 \%$ CI: 1.377-25.226), which means the children with light-intensity physical activity were more likely to experience obesity 5.9 times greater than those who had moderate-intensity physical activity.

Table 1. Characteristics of school-age children year $2020(n=37)$

\begin{tabular}{lcc} 
Characteristics & Frequency & Percentage (\%) \\
Sex & & \\
$\quad$ Male & 23 & 62.2 \\
$\quad$ Female & 14 & 37.8 \\
Dietary intake & & \\
$\quad$ Excessive & 20 & 54.1 \\
$\quad$ Inadequate & 17 & 45.9 \\
\hline Physical activity & & \\
$\quad$ Light & 22 & 59.5 \\
$\quad$ Moderate & 15 & 40.5 \\
BMI & & \\
$\quad$ Obesity $\left(\geq 30.0 \mathrm{~kg} / \mathrm{m}^{2}\right)$ & 19 & 51,4 \\
$\quad$ Normal $\left(18,5-24,9 \mathrm{~kg} / \mathrm{m}^{2}\right)$ & 18 & 48,6 \\
\hline
\end{tabular}

Table 2. Correlation between Dietary Intake and Obesity in School-age Children $(\mathbf{n}=37)$.

\begin{tabular}{|c|c|c|c|c|c|c|}
\hline \multirow[t]{3}{*}{ Dietary Intake } & \multicolumn{4}{|c|}{ Obesity } & \multirow[t]{3}{*}{ P-value } & \multirow[t]{3}{*}{ OR (CI 95\%) } \\
\hline & \multicolumn{2}{|c|}{ Obese } & \multicolumn{2}{|c|}{ Normal } & & \\
\hline & n & $\%$ & n & $\%$ & & \\
\hline Excessive & 14 & 73.7 & 6 & 33.3 & 0.033 & 5.600 \\
\hline Inadequate & 5 & 26.3 & 12 & 66.7 & & $(1.360-23.059)$ \\
\hline Total & 19 & 100 & 18 & 100 & & \\
\hline \multicolumn{7}{|l|}{ Physical Activity } \\
\hline Light & 15 & 78.9 & 7 & 38.9 & 0.032 & 5.893 \\
\hline Moderate & 4 & 21.1 & 11 & 61.1 & & $(1.377-25.226)$ \\
\hline Total & 19 & 100 & 18 & 100 & & \\
\hline
\end{tabular}


The score distribution of PSQI between obese children and non-obese children was presented in the following table.

Table 3 showed the score gap for each PSQI component based on the median. Statistical test using Mann-Whitney test resulted pvalue $>0,05$ indicating that there was no difference of PSQI components' scores between obese children and non-obese children for subjective sleep quality, sleep latency, sleep duration, sleep disturbance, and daytime dysfunction. The component of use sleep medication cannot be analyzed further because the data was homogeny, i.e. all respondents stated that they never consume any sleeping pill. The analysis of habitual sleep efficiency using Mann-Whitney test resulted $\mathrm{p}$-value $=0.022<(0,05)$ indicating $\mathrm{H}_{0}$ was rejected, which means there was score gap of habitual sleep efficiency between obese group and non-obese (normal) group where the median of obese group was higher than the non-obese group. The correlation of global PSQI scores was presented in Table 3.

From Table 4, it can be seen that most of the obese children, 12 out of 19 , had poor sleep quality $(63.2 \%)$, while most of the nonobese (normal) children, 15 out of 18 , had good sleep quality $(83.3 \%)$. Based on the chi-square statistic, it resulted $\mathrm{p}$-value $=$ $0.011<(0,05)$ indicating $\mathrm{H}_{0}$ was rejected, which means there was a correlation between sleep quality and obesity, with $\mathrm{OR}=8.571$ (95\% CI: 1.818-40.423), which means the children with poor sleep quality were likely to experience obesity 8.6 times greater than children with good sleep quality.

The final multivariate result found that the variable from sleep quality that was significantly correlated to obesity in school-age children was the habitual sleep efficiency. The dominant variable related to obesity in school-age children was habitual sleep efficiency with $\mathrm{OR}=12.36495 \% \mathrm{CI}$ [1.352-113.028], which means the children who had poor habitual sleep efficiency were likely to experience obesity 12 times greater than those who had good habitual sleep efficiency. The final model is described in Table 5.

\section{Discussion}

This finding showed that most of the obese children, 14 out of 19 , were male $(73.7 \%$ ), while among the non-obese children (normal), both male and female were in equal proportion. Follow-up testing by using chi-square test resulted p-value $=0.252>(0,05)$ indicating there was no correlation between sex and obesity in school-age children. It was because the respondents were predominantly by male, but most of the respondents in obese group was male. Similar to a study conducted A study by Fikri and Husna mentioned that the obese group was dominated by male, i.e. $56.8 \% .{ }^{17}$ Boy's height was significantly higher than girl, i.e. $53.9 \%{ }^{18}$ Boys preferred playing computer rather than doing outdoor activity, which was different from girls who preferred doing outdoor activity. ${ }^{19}$

In this study, most of the school-age children had excessive dietary intake. It was influenced by the environmental factor and the parent's socioeconomic status. The parents did not cultivate good eating habit to their children, they tended to give all the children wanted regardless of its nutritional value. School-age children can imitate their family diet; thus, the choices and needs should be managed. Parents tended to manage their children's meals based on the types, quantity, and eating schedule. In line with a study by Marfuah, Hadi, and Huriyati which found that obese children had higher daily intake than non-obese children, ${ }^{20}$ obese children had higher energy intake, $(\geq 110 \% \mathrm{AKG}) 1.6(\mathrm{OR}=1.61,95 \% \mathrm{CI}=1.11$ 2.35) times higher than non-obese children.

Students tended to do less physical activity, such as indoor light-intensity activity, playing video games, or watching TV after school until the evening. The finding showed that most of the respondents did light-intensity activity (59.5\%), i.e. $<5,000$ steps/day and none of them did vigorous-intensity activity because

Table 3. PSQI Score Gap in School-age Children $(n=37)$.

\begin{tabular}{lccc} 
Median of PSQI Components & Group & P-value \\
Subjective sleep quality & $2(0-3)$ & $1(0-3)$ & 0.057 \\
Sleep latency & $1(0-3)$ & $1(0-3)$ & 0.210 \\
\hline Sleep duration & $0(0-3)$ & $0(0-1)$ & 0.391 \\
Habitual sleep efficiency & $1(0-3)$ & $0(1-2)$ & 0.022 \\
\hline Sleep disturbance & $1(0-1)$ & $1(0-2)$ & 0.916 \\
Use of sleep medication & - & $1(0-2)$ & 1.000 \\
\hline Daytime disfunction & $1(0-3)$ & 0.499 \\
\hline
\end{tabular}

Table 4. Correlation between PSQI global score and obesity in school-age children $(\mathbf{n}=37)$.

\begin{tabular}{|c|c|c|c|c|c|c|}
\hline \multirow[t]{3}{*}{ Sleep Quality } & \multicolumn{4}{|c|}{ Obesity } & \multirow[t]{3}{*}{ P-value } & \multirow[t]{3}{*}{ OR (CI 95\%) } \\
\hline & & & & & & \\
\hline & n & $\%$ & $\mathrm{n}$ & $\%$ & & \\
\hline Poor & 12 & 63.2 & 3 & 16.7 & 0.011 & 8.571 \\
\hline Good & 7 & 36.8 & 15 & 83.3 & & $(1.818-40.423)$ \\
\hline Total & 19 & 100 & 18 & 100 & & \\
\hline
\end{tabular}

Table 5. Final model of multivariate factor analysis related to obesity in school-age children $(\mathbf{n}=37)$.

\begin{tabular}{lccccc} 
Variable & B & P-value & OR (Exp. B) & $95 \%$ CI & R $^{2}$ \\
Habitual sleep efficiency & 2.515 & 0.026 & 12.364 & $1.352-113.028$ & 0.351 \\
Constant & -0.435 & & & \\
\hline
\end{tabular}


their weight cannot support their body to actively move. Globally, many children had physical activity decline. The benefits of physical activity for children and adolescence play an important role for their health in adulthood, such as increasing bone mineral density and indirectly preventing overweight. The advancement of technology also contributes to children's playing activity. ${ }^{21}$ In the last decade, there was a major change in children's activity, where they spent more time in front of TV and sitting to play video games from their phone or tablet. ${ }^{22}$

The multivariate result of this study showed that the most dominant factor in children sleep quality related to obesity was the habitual sleep efficiency with $\mathrm{OR}=12.364$. Sleep efficiency in younger children was associated with neurocognitive, social-emotional, and physical health development, and also family plays an important role to prevent sleep problems during early development. ${ }^{23}$

This finding was in line with Ogilvie and Patel (2017) who defined low sleep efficiency as the percentage of sleep interval spent to sleep in relation to obesity. ${ }^{24}$ Children who had low sleep efficiency might experience sleep disturbance stage N3 selectively. The low sleep efficiency was also associated with bloated stomach through potential mechanism, such as autonomic nervous system and hypothalamic pituitary adrenal axis.

This study found that the lack of sleep was one of the risk factors of overweight and obesity. Lack of sleep might disrupt hormonal regulation in the body and cause increased appetite, which causes increased energy intake that might trigger the obesity. Similar to a study conducted by Sagala, Sofyani, and Supriatmo which proved that sleep quality contributes to the prevalence of obesity after being controlled by the calorie intake variable. ${ }^{25} \mathrm{~A}$ study by Marfuah proved that the primary school-age children who did not have good sleep quality were likely to experience obesity 2.23 times greater than children with good sleep quality. ${ }^{20}$

In optimizing our health, we implement healthy lifestyle to find the optimal balance of healthy behavior and it affects one to another. For instance, physical activities like aerobic were proven to improve sleep quality and eating behavior. Watching television was proven to disrupt sleep and associated with excessive dietary intake. Lack of sleep might decrease the physical activity due to tired feeling and is associated with more screen time at night and increase dietary intakes. ${ }^{26}$

Due to the lack of sleep, the brain activity in related area, including putamen, thalamus, insula, and prefrontal cortex as the response to food stimulation and unhealthy food choice might cause weight gain. ${ }^{27}$ Short sleep duration and sleep disturbance disrupt the neuroendocrinal system which lead to the increased appetite, increased sensitivity to food stimulation, and eventually excessive energy intake. ${ }^{28}$

Based on the discussion and findings related to the correlation between sleep quality and obesity in school-age children, it can be concluded that lack of sleep was one of the risk factors of overweight and obesity. Lack of sleep might disrupt hormonal regulation in body and cause increased appetite, which causes increased energy intake that might trigger the obesity. Without parent's help, a good sleep quality will not be achieved. Therefore, the researcher suggests the pediatric nurses to cooperate with the parents in managing the children sleep schedule. However, there were correlations between dietary intake, physical activity, sleep quality, and obesity in school-age children. The most dominant factor of sleep quality related to obesity in school-age children was the habitual sleep efficiency $(\mathrm{OR}=12.354)$.
Correspondence: Dessie Wanda, Department of Pediatric Nursing, Faculty of Nursing, Universitas Indonesia, Jalan Prof. Dr. Bahder Djohan, UI Depok Campus, West Java 16424, Indonesia. Tel.+62.21.78849120 - Fax.+62.21.7864124. Email: dessie@ui.ac.id Key words: Obesity; school-age children; sleep quality.

Contributions: All authors contributed equally. DW, EA supervised conceptualization and design the study, revising it critically for important intellectual content, final approval. BE: concept and design analysis and interpretation of data, drafting manuscript.

Conflict of interest: The authors declare no conflict of interest, financial or otherwise.

Acknowledgments: The author would to thank all respondents and all parties who had helped the completion of this research. Our deepest gratitude was also expressed to the Direktorat Riset dan Pengembangan Universitas Indonesia for funding this research with fund PUTI Saintekes 2020 Number: NKB-4634/UN2.RST/ HKP.05.00/2020

Ethics Approval: This study has been approved by Ethics Committee of Faculty of Nursing Universitas Indonesia, Depok with Number: SK-41/UN.2.F12.D1.2.1/ETIK.FIK.2020. For respondent who participated in the research, fill out the informed consent form.

Availability of data and material: The datasets analyzed in this study are available from the corresponding author on reasonable request.

Conference presentation: This final manuscript has been presented at $7^{\text {th }}$ Virtual Biennial International Nursing Conference, Faculty of Nursing, Universitas Indonesia on September $24^{\text {th }}$, October $30^{\text {th }}$, November $16^{\text {th }} 2020$.

Received for publication: 15 January 2021

Accepted for publication: 12 March 2021.

o Copyright: the Author(s), 2021

Licensee PAGEPress, Italy

Journal of Public Health Research 2021; 10(s1):2331

doi:10.4081/jphr.2021.2331

This work is licensed under a Creative Commons Attribution NonCommercial 4.0 License (CC BY-NC 4.0).

\section{References}

1. Cataldo R, Huang J, Calixte R, et al. Effects of overweight and obesity on motor and mental development in infants and toddlers. Pediatr Obes 2016;11:389-96.

2. Ng M, Fleming T, Robinson M, et al. Global, regional, and national prevalence of overweight and obesity in children and adults during 1980-2013: a systematic analysis for the Global Burden of Disease Study 2013. Lancet 2014;384:766-81.

3. Hamann A. Aktuelles zur adipositas (mit und ohne diabetes). Diabetologe 2017;13:331-41.

4. Greydanus DE, Agana M, Kamboj MK, et al. Pediatric obesity: current concepts. Dis Mon 2018;64:98-156.

5. Helble M, Sato A. Wealthy but unhealthy overweight and obesity in Asia and the Pacific: trends, costs, and policies for better health. Tokyo: Asian Development Bank Institute; 2018.

6. Lindsay AC, Sitthisongkram S, Greaney ML, et al. Nonresponsive feeding practices, unhealthy eating behaviors, and risk of child overweight and obesity in Southeast Asia: a sys- 
tematic review. Int J Environ Res Public Health 2017;14:436.

7. Schienkiewitz A, Brettschneider AK, Damerow S, Schaffrath Rosario A. Overweight and obesity among children and adolescents in Germany. Results of the cross-sectional KiGGS Wave 2 study and trends. J Health Monitoring 2018;3:15-22.

8. de la Haye K, Dijkstra JK, Lubbers MJ, et al. The dual role of friendship and antipathy relations in the marginalization of overweight children in their peer networks: The TRAILS Study. PLoS One 2017;12:e178130.

9. Camargos ACR, Mendonça VA, de Andrade CA, et al. Overweight and obese infants present lower cognitive and motor development scores than normal-weight peers. Res Dev Disabil 2016;59:410-6.

10. Azizah AN, Sulchan M. Kadar C-reactive protein (CRP) pada remaja putri stunted obesity di pedesaan Jepara. J Nutr College 2017;5:71-6.

11. Bhuiyan MU, Zaman S, Ahmed T. Risk factors associated with overweight and obesity among urban school children and adolescents in Bangladesh: a case-control study. BMC Pediatr 2013;13:72.

12. Muscogiuri G, Barrea L, Annunziata G, Di Somma C, Laudisio D, Colao A, et al. Obesity and sleep disturbance: the chicken or the egg? Crit Rev Food Sci Nutr 2019;59:2158-65.

13. Susanto H. Durasi lama tidur pada remaja di dua negara ASEAN. In: Suyanto, editor. Buku proceeding Unissula nursing conference. 1st Unissula Nursing Conference Call for Paper; 2018 Feb 24; FIK Unissula, Semarang. Semarang: Unissula Press; 2018. p. 11-6.

14. Buysse DJ, Reynolds CF 3rd, Monk TH, Berman SR, Kupfer DJ. The Pittsburgh Sleep Quality Index: a new instrument for psychiatric practice and research. Psychiatry Res 1989;28:193213.

15. Moghaddam JF, Nakhaee N, Sheibani V, Garrusi B, Amirkafi A. Reliability and validity of the Persian version of the Pittsburgh Sleep Quality Index (PSQI-P). Sleep Breath 2012;16:79-82.

16. Wilson AM, Magarey AM, Mastersson N. Reliability and relative validity of a child nutrition questionnaire to simultaneously assess dietary patterns associated with positive energy balance and food behaviours, attitudes, knowledge and environments associated with healthy eating. Int J Behav Nutr Phys
Act 2008;5:5.

17. Fikri HK, Husna CA. Hubungan kualitas tidur dengan obesitas pada anak sekolah dasar (SD) negeri di Desa Kampung Jawa Lama dan Lancang Garam Kota Lhokseumawe. Averrous Jurnal Kedokteran dan Kesehatan Malikussaleh 2018;4:41-9.

18. Wang J, Adab P, Liu W, et al. Prevalence of adiposity and its association with sleep duration, quality, and timing among 9 12-year-old children in Guangzhou, China. J Epidemiol 2017;27:531-7.

19. Garmy P, Clausson EK, Nyberg P, Jakobsson U. Insufficient sleep is associated with obesity and excessive screen time amongst ten-year-old children in Sweden. J Pediatr Nurs 2018;39:e1-e5.

20. Marfuah D, Hadi H, Huriyati E. Durasi dan kualitas tidur hubungannya dengan obesitas pada anak sekolah dasar di Kota Yogyakarta dan Kabupaten Bantul. Jurnal Gizi dan Dietetik Indonesia 2013;1:93-101.

21. Nassonko MM. Effect of the new digital era on child development: case study of the teachers of Gateway Nursery and Primary School, Entebbe. Unpublished thesis. Kampala: Makerere University; 2019.

22. Pyper E, Harrington D, Manson H. The impact of different types of parental support behaviours on child physical activity, healthy eating, and screen time: a cross-sectional study. BMC Public Health 2016;16:568.

23. Mindell JA, Williamson AA. Benefits of a bedtime routine in young children: sleep, development, and beyond. Sleep Med Rev 2018;40:93-108.

24. Ogilvie RP, Patel SR. The epidemiology of sleep and obesity. Sleep Health 2017;3:383-8.

25. Sagala NJ, Sofyani S, Supriatmo S. Association between sleep quality and obesity in adolescents. Paediatrica Indonesiana 2017;57:41-6.

26. Chaput JP, Dutil C. Lack of sleep as a contributor to obesity in adolescents: impacts on eating and activity behaviors. Int $\mathrm{J}$ Behav Nutr Phys Act 2016;13:103.

27. St-Onge MP, Mikic A, Pietrolungo CE. Effects of diet on sleep quality. Adv Nutr 2016;7:938-49.

28. Schmid SM, Hallschmid M, Schultes B. The metabolic burden of sleep loss. Lancet Diabetes Endocrinol 2015;3:52-62. 